Research Article

\title{
Nonlinear Dynamic Analysis of the Cutting Process of a Nonextensible Composite Boring Bar
}

\author{
Bole Ma $\mathbb{i D}^{1,2}$ and Yongsheng Ren $\mathbb{i D}^{2}$ \\ ${ }^{1}$ School of Aerospace Engineering, Beijing Institute of Technology, Beijing, China \\ ${ }^{2}$ College of Mechanical and Electronic Engineering, Shandong University of Science and Technology, Qingdao, China
}

Correspondence should be addressed to Yongsheng Ren; renys@sdust.edu.cn

Received 18 January 2020; Revised 18 August 2020; Accepted 17 September 2020; Published 28 October 2020

Academic Editor: Francesco Franco

Copyright (c) 2020 Bole Ma and Yongsheng Ren. This is an open access article distributed under the Creative Commons Attribution License, which permits unrestricted use, distribution, and reproduction in any medium, provided the original work is properly cited.

\begin{abstract}
A nonlinear dynamic analysis of the cutting process of a nonextensible composite cutting bar is presented. The cutting bar is simplified as a cantilever with plane bending. The nonlinearity is mainly originated from the nonextensible assumption, and the material of cutting bar is assumed to be viscoelastic composite, which is described by the Kelvin-Voigt equation. The motion equation of nonlinear chatter of the cutting system is derived based on the Hamilton principle. The partial differential equation of motion is discretized using the Galerkin method to obtain a 1-dof nonlinear ordinary differential equation in a generalized coordinate system. The steady forced response of the cutting system under periodically varying cutting force is approximately solved by the multiscale method. Meanwhile, the effects of parameters such as the geometry of the cutting bar (including length and diameter), damping, the cutting coefficient, the cutting depth, the number of the cutting teeth, the amplitude of the cutting force, and the ply angle on nonlinear lobes and primary resonance curves during the cutting process are investigated using numerical calculations. The results demonstrate that the critical cutting depth is inversely proportional to the aspect ratio of the cutting bar and the cutting force coefficient. Meanwhile, the chatter stability in the milling process can be significantly enhanced by increasing the structural damping. The peak of the primary resonance curve is bent toward the right side. Due to the cubic nonlinearity in the cutting system, primary resonance curves show the characteristics of typical Duffing's vibrator with hard spring, and jump and multivalue regions appear.
\end{abstract}

\section{Introduction}

Cutting is an indispensable key step in processing and manufacturing of mechanical parts. In spite of significant progresses in advanced manufacturing technology (AMT) and increasing applications in high-tech domains such as aerospace and automobile, chatter in cutting is a main issue that seriously limits the cutting efficiency of the machining tools.

Induced by dynamic instability in closed-loop systems consisting of cutting tools and workpieces, chatter can be categorized as regenerative chatter and mode-coupling chatter. The regenerative chatter is the one with most severe hazard. The occurrence of chatter can lead to the reduction of cutting specification and processing quality and even seriously cause damage to the cutting tools. Therefore, an accurate model for chatter analysis is of great significance to effective chatter control.

Previous studies demonstrated that the critical cutting depth is proportional to the dynamic stiffness of the boring bar [1]. Therefore, passive control methods such as various dynamic vibration absorbers $[2,3]$ and impact dampers [4] have been proposed to reduce the chatter of the boring bar and enhance the cutting stability. These control methods are highly effective under certain conditions. However, an additive system is required, and the parameters of the absorbers are highly dependent on the state machine tools, thereby restricted by the installation conditions of the cutting system in many cases. In fact, changing the structural dynamic characteristics of the boring bar by adopting new 
materials seems to be an effective approach worth exploring. It is well known that composite materials are featured by high static stiffness, high damping, and high specific stiffness. Nagano et al. [5] developed a finite element analysis model for a composite boring bar (steel core-embedded pitch-based carbon fiber reinforced plastic) and investigated the effects of the steel core shape on stiffness and natural frequency. They claimed that the aspect ratio of the chatterfree composite boring bar was approximately 2 times greater than that of a metal boring bar. Lee and Yun Hwang [6] conducted vibrating experiments to investigate the dynamic characteristics of composite boring bars consisting of damping core, carbon fiber epoxy composite main shaft, and steel cover. The results indicated that the dynamic stiffness and the cutting capability of the composite boring bar were approximately $30 \%$ and $33 \%$ higher than those of traditional tungsten carbide boring bars, respectively.

Most of current models and analyses regarding cutting chatter are based on the linear theory. Taylor [7] reported chatter for the first time and predicted that chatter will be the limit of productivity. However, no theoretical explanations of the chatter phenomenon were reported until 1960s. Based on the linear theory, scholars identified the chatter stability boundary and divided the process parameter spaces (including cutting depth and speed of the main shaft) into stable and unstable regions [8-11]. By introducing timedelay instable terms into cutting force, Tobias and Fishnick [8] proposed the regenerative theory, which is recognized as the most thorough explanation of the chatter phenomenon. Altintas [12] and Budak and Altintas [13,14] constructed the prediction theory of chatter in lathing, milling, and drilling process based on the regenerative effect and experimental modal analysis.

As some important behaviors in cutting process cannot be well predicted based on the linear theory, nonlinear modeling of the cutting system has attracted great attention in recent years. The nonlinearity in a cutting system is mainly originated from structural nonlinearity, quadratic and three-order nonlinear time-delay cutting force, and power function cutting force [15-18]. Hanna and Tobias [15] proposed a time-delay nonlinear model with quadratic and three-order structural stiffness and cutting force. This study has stimulated scholars' great interests in global dynamics in this field. The main mathematical methods describing the nonlinearity of cutting systems include center manifold theory, bifurcation theory, perturbation analysis, phase portraits, and Poincaré section.

Using multiscale method, harmonic balance analysis, and Floquet theory, Pratt et al. investigated the model established by Stepan and Insperger [18] and concluded that the cubic structural nonlinearity may lead to subcritical Hopf bifurcation. Moradi and Movahhedy [19] focused on the different bifurcation types in the cutting process by taking the cutting tool wear and process damping into consideration. They constructed the two-degree-of-freedom (2-dof) linear model of the cutting tool, described the cutting force using a polynomial nonlinear model, and obtained the approximate analysis solution of primary resonance [20]. Based on a model similar to that proposed by
Budak and Altintas [13], Moradi and Vossoughi [21] analyzed forced vibration in milling process and discussed primary resonance, superharmonic resonance, and internal resonance. By taking cutting force and structural nonlinearity into account, Moradi and Movahhedy [19] investigated internal resonance and regenerative chatter in milling process. Jalili and Hesabi [22] constructed a 3D nonlinear structural model of the cutting tool by considering gyroscopic moment and rotational inertia and investigated main, subharmonic, and superharmonic resonance in milling systems by multiscale methods. By simplifying the cutting tool as a 2-dof model, Abootorabi and Ngo [23] reported a bifurcation analysis of the milling process with nonlinear cutting forces and regenerative characteristics. The local chatter characteristics of the system were analyzed using the multiscale method and harmonic balance method.

Zhang et al. [24-32] had done an in-depth study and obtained a number of results. Firstly, the global bifurcations and chaotic dynamics for the nonlinear nonplanar oscillations of a cantilever beam subjected to a harmonic axial excitation and transverse excitations at the free end are studied. Then, the nonlinear dynamics of a shell-shaped workpiece during high-speed milling is studied. Meanwhile, they analyzed the nonlinear dynamics of a thin-plate workpiece during milling process with cutting force nonlinearities.

Studies mentioned above show that regenerative chattering in cutting is featured by high nonlinearity. The effects of multiple nonlinear factors including cutting force and cutting tool structure have been taken into account, and the physical phenomenon can be well explained and described using the proposed complex nonlinear models. However, most studies are based on simple 1-dof or 2-dof lumped mass nonlinear models and focus on establishment and analysis of the cutting systems with isotropic metal cutting tools. In addition, the effects of structural damping of cutting tools are neglected in these current investigations.

This study focuses on nonlinear dynamics of the cutting process of nonextensible composite boring bars. The cutting bar is simplified as a cantilever with plane bending. The nonlinearity is originated from the assumption of the nonextensible cutting bar, and the material of the cutter bar is assumed to be viscoelastic composite material, which is described by the Kelvin-Voigt equation. The motion equation of the nonlinear chatter of cutting systems is derived based on the Hamilton principle. In order to obtain the closed-form solution to the vibration equation, the partial differential equation of motion is discretized using the Galerkin method, and a nonlinear ordinary differential motion equation in the generalized coordinate system is derived. The steady forced response of the cutting system under periodically varying cutting force is approximately solved by the multiscale method. The effects of parameters such as geometry of the cutting bar (including length and diameter), damping, cutting coefficient, cutting depth, number of the cutting teeth, and amplitude of the cutting force on nonlinear lobes and primary resonance response curves in milling process are investigated numerically. 


\section{Establishment of the Mathematical Model and Solution}

Figure 1 displays the structure of a composite boring bar with plane bending. We simplify the cutting bar model for the cantilever beam with plane bending in one principal direction, and the structure can vibrate only in the direction normal to the machined surface.

The kinetic energy of the composite boring bar can be written as follows:

$$
T=\frac{m}{2} \int_{0}^{L}\left(\dot{u}^{2}+\dot{v}^{2}\right) \mathrm{d} x,
$$

where $m$ denotes the mass of the cutting bar per unit length, $L$ denotes the length of the cutting bar, $u$ and $v$ denote the displacement of a point on the cross-section along $x$ and $y$ directions, respectively, and "." denotes the derivative with respect to $t$. $u$ and $v$ are also referred to as longitudinal and lateral displacements, respectively.

By neglecting shear strains, the strain at a point on the cross-section can be written as follows:

$$
\varepsilon_{x}=e-y \rho,
$$

where $y$ denotes the coordinates of the point on the crosssection and $\rho$ and $e$ denote the curvature and the strain along the central line of the cutting bar, respectively.

$$
e=\sqrt{\left(1+u^{\prime}\right)^{2}+v^{\prime 2}}-1
$$

where $u$ denotes the displacement of the cross-section along $x$ direction and ' denotes the partial derivative with respect to $x$.

The variation of the strain energy of the cutting bar can be expressed as follows:

$$
\delta U=\int_{0}^{L} \int_{A} \sigma_{x} \delta \varepsilon_{x} \mathrm{~d} A \mathrm{~d} x,
$$

where $\sigma_{x}$ denotes the stress component.

Assuming that the material of the cutting bar is a viscoelastic composite, the stress-strain relation obeys the Kelvin-Voigt equation:

$$
\sigma_{x}=E_{k} \varepsilon_{x}+C_{k} \dot{\varepsilon}_{x}
$$

where $E_{k}$ and $C_{k}$ denote the elasticity modulus and the damping coefficient of the $k$-th layer on the cross-section, respectively.

It is assumed that the cutting bar is nonextensible, i.e., $e=0$, and the following expression can be obtained:

$$
u^{\prime}=\sqrt{1-v^{\prime 2}}-1 \approx-\frac{1}{2} v^{\prime 2} .
$$

$\rho$ can be approximated as follows:

$$
\rho \approx v^{\prime \prime}-v^{\prime} u^{\prime \prime}-u^{\prime} v^{\prime \prime}-v^{\prime 2} v^{\prime \prime} \approx v^{\prime \prime}+\frac{1}{2} v^{\prime \prime} v^{\prime 2} .
$$

$u$ is solved using equation (6), and the derivative of $u$ with respect to time is obtained. By substituting the

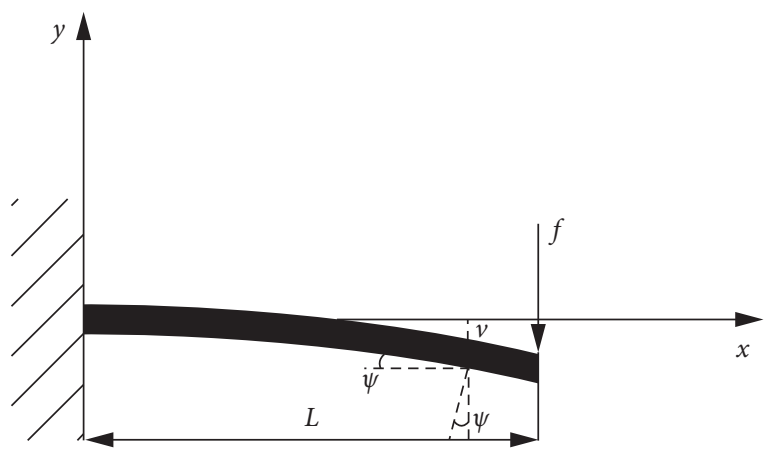

FIgURE 1: Structure of the composite boring bar with plane bending.

derivative into equation (1), the following expression can be derived:

$$
T=\frac{m}{2} \int_{0}^{L}\left[\left(\frac{\partial}{\partial t} \int_{0}^{x} \frac{1}{2} v^{\prime 2} \mathrm{~d} x\right)^{2}+\dot{v}^{2}\right] \mathrm{d} x
$$

According to the equations of kinetic energy and strain energy, the motion equation can be obtained based on the Hamilton principle:

$$
\begin{aligned}
& m \ddot{v}+C I \dot{v}^{(4)}+E I v^{(4)}+\frac{m}{2}\left[v^{\prime} \int_{L}^{x} \int_{0}^{x}\left(\dot{v}^{\prime 2}+v^{\prime} \ddot{v}^{\prime}\right) \mathrm{d} x \mathrm{~d} x\right]^{\prime} \\
& +E I\left(v^{\prime}\left(v^{\prime} v^{\prime \prime}\right)^{\prime}\right)^{\prime}+C I\left(\frac{1}{2} \dot{v}^{\prime \prime} v^{\prime 2}+v^{\prime \prime} v^{\prime} \dot{v}^{\prime}\right)=f(x, t),
\end{aligned}
$$

where the superscript (4) denotes the fourth-order partial derivative with respect to $x$ and $E I$ and $C I$ denote the equivalent bending stiffness and damping coefficient of the cross-section of the composite cutting bar, respectively. $f(x, t)=\Delta F(t) \delta(x-L)$, where $\delta$ is a Dirac function, and $\Delta F(t)$ denotes the cutting force at the end of the cutting bar $(x=L)$ :

$$
\begin{aligned}
\Delta F(t)= & K_{t} w h(t)=K_{t} w\left[h_{0}-(v(L, t)-v(L, t-\tau))\right] \\
& +F \cos \Omega t
\end{aligned}
$$

where $K_{t}$ denotes the cutting coefficient, $w$ denotes the cutting depth, $h(t)$ denotes the dynamic cutting thickness, $\tau$ denotes the rotation period of the cutting teeth $(\tau=2 \pi / N \Omega)$, $N$ denotes the number of teeth, $\Omega$ denotes the rotation speed, and $F$ denotes the amplitude of periodic component in the cutting force. The effects of the static cutting thickness $h_{0}$ were not considered in equation (10). Define $h_{0}=0$.

In order to obtain the approximate solution to equation (9), it is simplified using the Galerkin method. Let

$$
v=\phi_{1}(x) V(t)
$$

By substituting equation (11) into equation (9), the following expression can be derived using the Galerkin method: 


$$
\begin{aligned}
A_{1} \ddot{V} & +\widehat{c} A_{2} \dot{V}+\widehat{k} A_{2} V+A_{3} V\left(\dot{V}^{2}+V \ddot{V}\right)+\widehat{k} A_{4} V^{3}+\widehat{c} A_{5} V^{2} \dot{V} \\
& =-\frac{K_{t} w}{m} A_{6}\left(V-V_{\tau}\right)+\frac{F}{m} A_{7} \cos \Omega t,
\end{aligned}
$$

where

$$
\begin{aligned}
A_{1} & =\int_{0}^{L} \phi_{1}^{2} \mathrm{~d} x, \\
A_{2} & =\int_{0}^{L} \phi_{1} \phi_{1}^{(4)} \mathrm{d} x \\
A_{3} & =\frac{1}{2} \int_{0}^{L} \phi_{1}\left[\phi_{1}^{\prime} \int_{L}^{x} \int_{0}^{x} \phi_{1}^{2} \mathrm{~d} x \mathrm{~d} x\right]^{\prime} \mathrm{d} x, \\
A_{4} & =\int_{0}^{L} \phi_{1}\left[\phi_{1}^{\prime}\left(\phi_{1}^{\prime} \phi_{1}^{\prime \prime}\right)^{\prime}\right]^{\prime} \mathrm{d} x, \\
A_{5} & =\frac{3}{2} \int_{0}^{L} \phi_{1}\left(\phi_{1}^{\prime 2} \phi_{1}^{\prime \prime}\right)^{\prime \prime} \mathrm{d} x, \\
A_{6} & =\phi_{1}^{2}(L) \\
A_{7} & =\phi_{1}(L), \\
V & =V(t), \\
V_{\tau} & =V(t-\tau) .
\end{aligned}
$$

Let

$$
\begin{aligned}
\beta_{0} & =\frac{A_{2}}{A_{1}}, \\
\beta_{1} & =\frac{A_{3}}{A_{1}}, \\
\beta_{2} & =\frac{A_{4}}{A_{1}}, \\
\beta_{3} & =\frac{A_{5}}{A_{1}}, \\
\beta_{4} & =\frac{A_{6}}{A_{1}} \\
\beta_{5} & =\frac{A_{7}}{A_{1}}, \\
\widehat{c} & =\frac{C I}{m}, \\
\widehat{k} & =\frac{E I}{m}, \\
\widehat{F} & =\frac{F}{m}, \\
W & =\frac{K_{t} w}{m} .
\end{aligned}
$$

According to the linear vibration theory of 1-dof systems, the following expression can be obtained:

$$
\begin{aligned}
& \frac{E I}{m}=\frac{A_{1}}{A_{2}} \omega_{1}^{2}, \\
& \frac{C I}{m}=\sqrt{\frac{A_{1}}{A_{2}}} \frac{L^{2}}{I} \eta \omega_{1},
\end{aligned}
$$

where $\omega_{1}$ and $\eta$ denote the first-order natural frequency and the loss factor of the composite cutting bar, respectively.

Equation (12) can be rewritten as follows:

$$
\begin{aligned}
\ddot{V} & +\widehat{c} \beta_{0} \dot{V}+\widehat{k} \beta_{0} V+\beta_{1} V\left(\dot{V}^{2}+V \ddot{V}\right)+\widehat{k} \beta_{2} V^{3}+\widehat{c} \beta_{3} V^{2} \dot{V} \\
& =-W_{c} \beta_{4}\left(V-V_{\tau}\right)+\widehat{F} \beta_{5} \cos \Omega t .
\end{aligned}
$$

In order to investigate the nonlinear chatter stability of cutting systems, we let the periodic exciting force in equation (16) equal to 0 and numerical integration of the equation is performed to plot the stability lobes.

To acquire the approximate solution to primary resonance of the system, perturbation analysis is conducted on equation (16) by the multiscale method. By introducing the small parameter $\varepsilon$, equation (16) can be rewritten as follows:

$$
\begin{aligned}
\ddot{V} & +\varepsilon \widehat{\varepsilon} \beta_{0} \dot{V}+\widehat{k} \beta_{0} V+\varepsilon \beta_{1} V\left(\dot{V}^{2}+V \ddot{V}\right)+\varepsilon \widehat{k} \beta_{2} V^{3}+\varepsilon \widehat{\varepsilon} \beta_{3} V^{2} \dot{V} \\
& =-\varepsilon W_{c} \beta_{4}\left(V-V_{\tau}\right)+\varepsilon \widehat{F} \beta_{5} \cos \Omega t .
\end{aligned}
$$

Meanwhile, the detuning parameter $\sigma$ is introduced to express the nearness of $\omega_{1}$ to $\Omega$ quantitatively:

$$
\Omega=\omega_{1}+\varepsilon \sigma .
$$

By Laplace transform and Pade approximation $\left(e^{-s \tau} \approx 1-s \tau\right)$ [21], $V-V_{\tau}$, which is the time-delay term in equation (17), is simplified and equation (17) can be rewritten as follows:

$$
\begin{aligned}
\ddot{V} & +\varepsilon\left(\widehat{c} \beta_{0}+\beta_{4} W_{c} \tau\right) \dot{V}+\widehat{k} \beta_{0} V+\varepsilon \beta_{1} V\left(\dot{V}^{2}+V \ddot{V}\right) \\
& +\varepsilon \widehat{k} \beta_{2} V^{3}+\varepsilon \widehat{c} \beta_{3} V^{2} \dot{V}=\varepsilon \widehat{F} \beta_{5} \cos \Omega t .
\end{aligned}
$$

The solution to equation (19) can be expanded according to $\varepsilon$ :

$$
V=V_{0}\left(T_{0}, T_{1}\right)+\varepsilon V_{1}\left(T_{0}, T_{1}\right)+\cdots,
$$

where $T_{0}=t$ and $T_{1}=\varepsilon$. $t$ denotes fast-varying and slowvarying time scales, respectively.

The chain rule of the time derivative is as follows:

$$
\begin{aligned}
& \dot{V}=D_{0} V_{0}+\varepsilon\left(D_{1} V_{0}+D_{0} V_{1}\right)+\cdots, \\
& \ddot{V}=D_{0}^{2} V_{0}+\varepsilon\left(2 D_{1} D_{0} V_{0}+D_{0}^{2} V_{1}\right)+\cdots,
\end{aligned}
$$

where $D_{i}^{j}=\partial^{j} / \partial T_{i}^{j}$. 


$$
\begin{gathered}
\varepsilon^{0}: D_{0}^{2} V_{0}+\widehat{k} \beta_{0} V_{0}=0, \\
\mathcal{\varepsilon}^{1}: D_{0}^{2} V_{1}+\left(\widehat{c} \beta_{0}+\beta_{4} W_{c} \tau\right) D_{0} V_{0}+\widehat{k} \beta_{0} V_{1} \\
=-2 D_{0} D_{1} V_{0}-\beta_{1} V_{0}\left[\left(D_{0} V_{0}\right)^{2}+\left(D_{0}^{2} V_{0}\right) V_{0}\right] \\
-\widehat{k} \beta_{2} V_{0}^{3}-\beta_{3} \widehat{c}\left(D_{0} V_{0}\right) V_{0}^{2}+\widehat{F} \beta_{5} \cos \Omega t .
\end{gathered}
$$

The solution to equation (22) is as follows:

$$
V_{0}=A\left(T_{1}\right) e^{j \omega_{1} T_{0}}+\bar{A}\left(T_{1}\right) e^{-j \omega_{1} T_{0}} .
$$

By substituting equation (24) into equation (22), the secular item is eliminated:

$$
\begin{aligned}
& 2 j \omega_{1} \dot{A}+\left(\widehat{c} \beta_{0}+\beta_{4} W_{c} \tau\right) j \omega_{1} A \\
& \quad+\left(3 \widehat{k} \beta_{2}+j \beta_{3} \widehat{c} \omega_{1}-2 \beta_{1} \omega_{1}^{2}\right) \bar{A} A^{2}+\frac{\widehat{F}}{2} \beta_{5} e^{j \sigma T_{1}}=0 .
\end{aligned}
$$

Let

$$
\begin{aligned}
& A=\frac{1}{2} a e^{j \psi}, \\
& \bar{A}=\frac{1}{2} a e^{-j \psi},
\end{aligned}
$$

where $a$ and $\psi$ are the functions of $T_{1}$, and they denote vibration amplitude and phase angle, respectively.

Let $\sigma T_{1}-\psi=\Gamma$. Equation (25) can be rewritten as follows:

$$
\begin{aligned}
& 2 j \omega_{1}\left(a^{\prime}+j a\left(\sigma-\Gamma^{\prime}\right)\right)+\left(\widehat{c} \beta_{0}+\beta_{4} W_{c} \tau\right) j \omega_{1} a \\
& +\left(3 \widehat{k} \beta_{2}+j \beta_{3} \widehat{c} \omega_{c}-2 \beta_{1} \omega_{c}^{2}\right) \frac{1}{4} a^{3}+\widehat{F} \beta_{5} e^{j \Gamma}=0 .
\end{aligned}
$$

The real and imaginary parts are separated:

$$
\begin{aligned}
-2 \omega_{1} a\left(\sigma-\Gamma^{\prime}\right)+c_{1} a^{3}= & \widehat{F} \beta_{5} \cos \Gamma 2 \omega_{1} a^{\prime}+\left(\widehat{c} \beta_{0}+\beta_{4} W_{c} \tau\right) a \\
& +c_{3} a^{3}=\widehat{F} \beta_{5} \sin \Gamma,
\end{aligned}
$$

where

$$
\begin{aligned}
& c_{1}=\frac{1}{4}\left(2 \beta_{1} \omega_{1}^{2}-3 \widehat{k} \beta_{2}\right), \\
& c_{3}=-\frac{1}{4} \beta_{3} \widehat{c} \omega_{1} .
\end{aligned}
$$

In order to solve steady-state response, let $a^{\prime}=\Gamma^{\prime}=0$ and $\Gamma$ is eliminated:

$$
\sigma=\frac{-c_{1} a^{3} \pm \sqrt{\left(\widehat{F} \beta_{5}\right)^{2}-\left[c_{3} a^{3}+\left(\widehat{c} \beta_{0} t+n \beta_{4} q W_{c} h \tau\right) \omega_{1} a\right]^{2}}}{2 a \omega_{1}} .
$$

\section{Numerical Results and Discussion}

3.1. Stability Lobes. The carbon fiber/epoxy resin composite boring bar is used in this case study, and the mechanical properties are listed in Table 1. The cutting stiffness
TABle 1: Mechanical properties of the carbon fiber/epoxy composite [33].

\begin{tabular}{lccccc}
\hline$\rho\left(\mathrm{kg} / \mathrm{m}^{3}\right)$ & $E_{11}(\mathrm{GPa})$ & $E_{22}(\mathrm{GPa})$ & $G_{12}(\mathrm{GPa})$ & $G_{23}(\mathrm{GPa})$ & $\nu_{12}$ \\
\hline 1750 & 380 & 5.1 & 5.5 & 5.5 & 0.29 \\
\hline
\end{tabular}

coefficient per unit cutting depth and the number of cutting teeth are $2339.1 \mathrm{~N} / \mathrm{nm}^{2}$ and $N=2$, respectively. The boring bar is a hollow one with $L=460 \mathrm{~mm}$. The outer and inner diameters of the cross-section are $60 \mathrm{~mm}$ and $40 \mathrm{~mm}$, respectively, and $\eta=0.032$, and the thickness of the crosssection is $10 \mathrm{~mm}(h=10 \mathrm{~mm})$. The composite boring bar consists of 16 laminate layers with equal thickness in the format of $[ \pm \theta]_{8}$. The ply angle is $0^{\circ}$.

The above basic set of values of the parameters for machining conditions and the composite cutting bar will subsequently be used to analyze the stability and steady-state response of nonlinear dynamics of the process.

Based on $L, D, \rho$, and $E$, the first-order natural frequency can be calculated by $\omega_{1}=(1.875)^{2} \sqrt{E I / \rho A L^{4}}$.

$m$ can be calculated as follows:

$$
\begin{gathered}
m=\pi \sum_{k=1}^{N} \rho_{k}\left(r_{k+1}^{2}-r_{k}^{2}\right), \\
E I=\frac{\pi}{4} \sum_{k=1}^{N} \bar{Q}_{11}\left(r_{k+1}^{4}-r_{k}^{4}\right),
\end{gathered}
$$

where $\bar{Q}_{11}$ denotes the off-axis stiffness coefficient of the k-th layer in the composite and the subscripts $r_{k}$ and $r_{k}+1$ denote internal and external diameters of the k-th layer. The detailed expression of $\bar{Q}_{11}$ is shown in Appendix.

The damping ratio can be calculated by the following:

$$
\varsigma=\frac{L^{2}}{2} \sqrt{\frac{A_{2}}{A_{1}} \eta} .
$$

With the nonlinear term in equation (16) eliminated, the lobes of the linear system can be plotted using the frequencydomain prediction method for stability lobes of 1-dof systems [12].

In order to obtain stability lobes of the nonlinear cutting system, let the periodic exciting force in equation (16) equals to 0 (i.e., $\widehat{F}=0$ ) and numerical integration is performed on the nonlinear time-delay equation. Based on the lobes of the linear system, the stability lobes of the nonlinear cutting system at given rotating speeds and cutting depths are determined through repeated trials.

Figure 2 displays the comparison of linear and nonlinear stability lobes. As observed, the maximum cutting depth of the nonlinear system exceeds that of the linear system. This can be attributed to the cubic nonlinear of the cutting bar, which increases the stiffness of the cutting system. Therefore, the threshold of stability is raised.

Figure 3 shows the positions of 12 points on the nonlinear stability parameter plane. Table 2 lists the cutting depths and rotating speeds at these points, and Figure 4 displays the time-history response curves of these 12 points. 


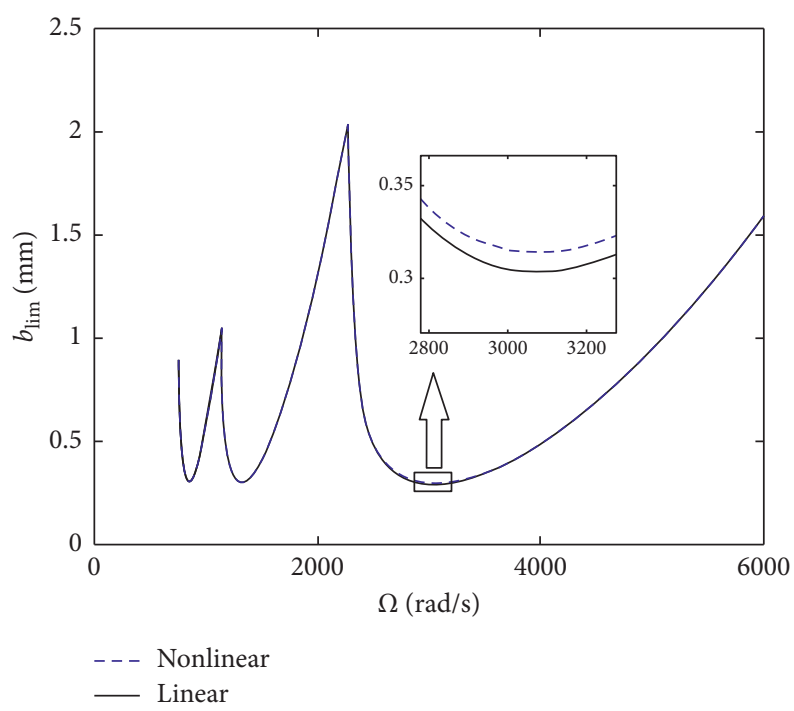

FIGURE 2: Lobes of the linear system of the nonextensible composite boring bar.

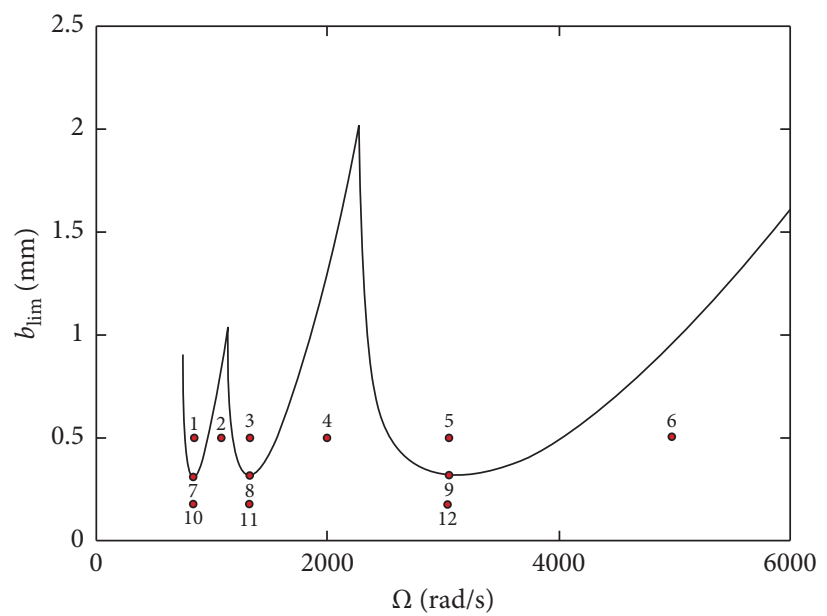

FIgure 3: Positions of the parameter points on the plane of the stability lobes.

TABLE 2: Corresponding values at these parameter points.

\begin{tabular}{|c|c|c|c|c|c|c|c|c|c|c|c|c|}
\hline Parameter point & 1 & 2 & 3 & 4 & 5 & 6 & 7 & 8 & 9 & 10 & 11 & 12 \\
\hline Rotating speed ( $\mathrm{rad} / \mathrm{s})$ & 844 & 1100 & 1325 & 2000 & 3071 & 5000 & 844 & 1325 & 3071 & 844 & 1325 & 3071 \\
\hline Nonlinear cutting depth $(\mathrm{mm})$ & 0.5 & 0.5 & 0.5 & 0.5 & 0.5 & 0.5 & 0.322 & 0.322 & 0.322 & 0.2 & 0.2 & 0.2 \\
\hline
\end{tabular}

The command ode45 in Matlab for solving delay differential equations is employed for numerical integral. As observed, Point 1 , Point 3 , and Point 5 are located in unstable regions. This parameter points are located within the region in the lobe curves, the unstable cutting region enclosed by the black solid line in Figure 3. The amplitude of the vibration response curve increases gradually with time but only within a certain range due to the suppression effect by the nonlinear stiffness. This is different from the case of the linear system. Point 7, Point 8, and Point 9 are located at the boundary of lobes, and their response amplitudes remain constant, suggesting critical stable cutting process. Point 2, Point 4, Point 6, Points 10, Point 11, and Point 12 are located in stable regions, and their time-history responses drop with time. The above-described prediction result based on frequency-domain lobe diagrams fits well with the prediction results from time-domain response curves.

Figure 5 shows the effect of the length of the cutting bar $L$ on the cutting stability boundary. As $L$ increases, the location of the stability lobes drops and the range of rotating speed 


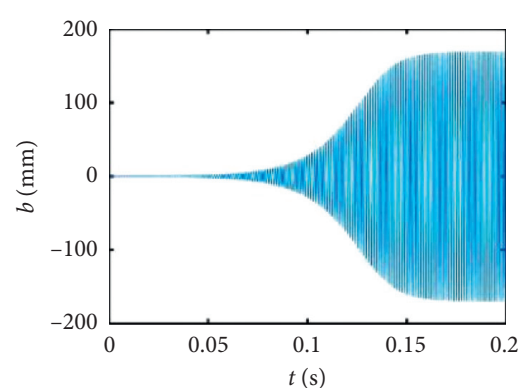

(a)

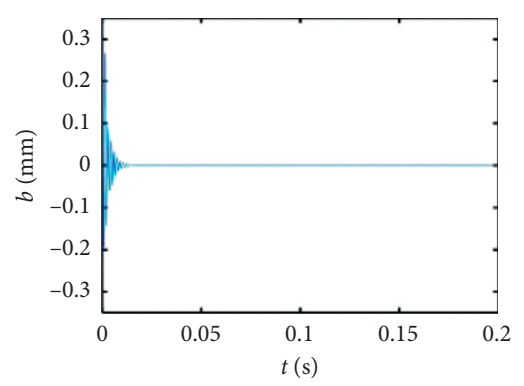

(d)

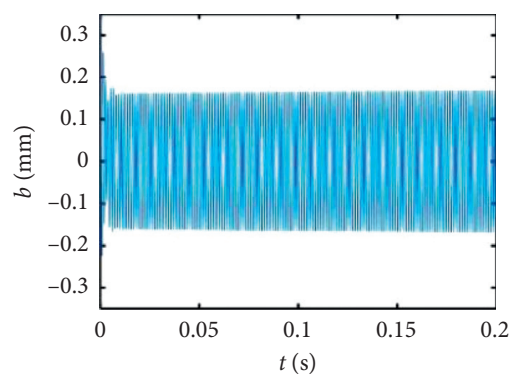

(g)

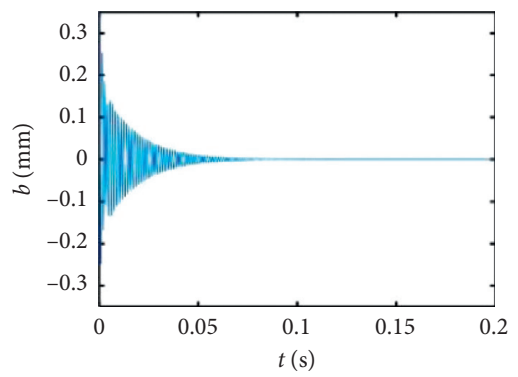

(j)

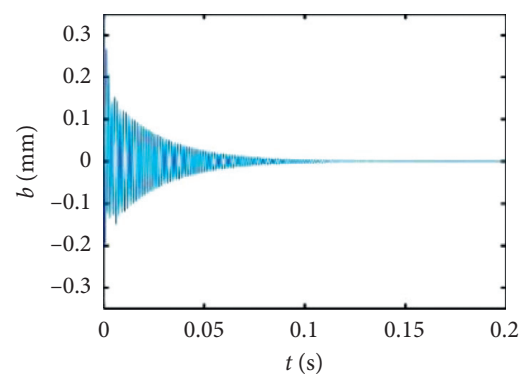

(b)

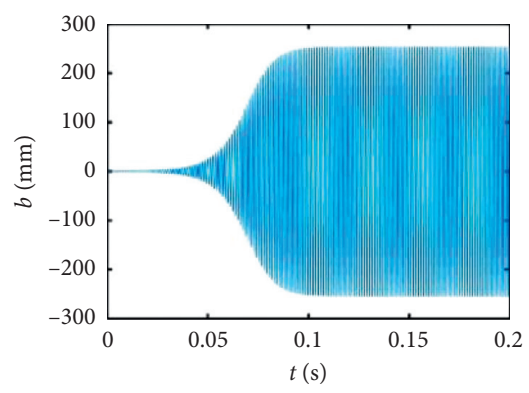

(e)

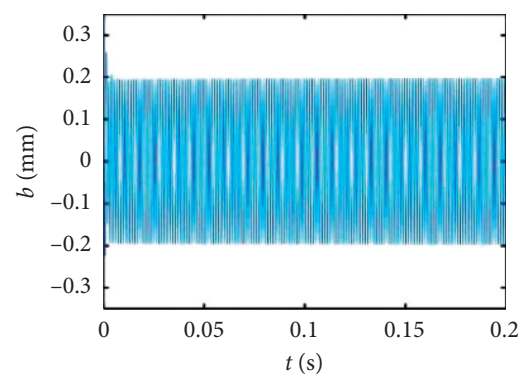

(h)

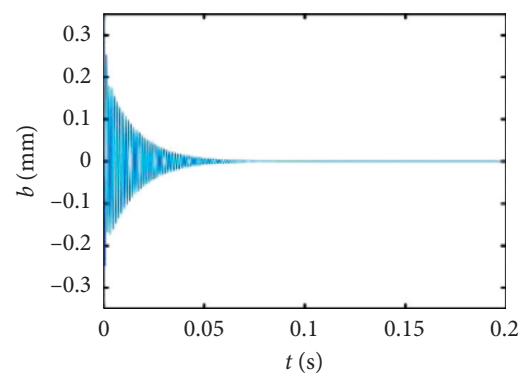

(k)

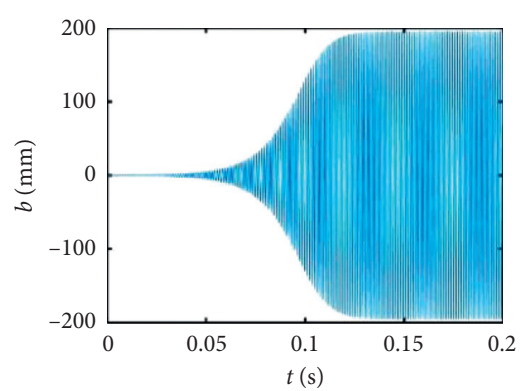

(c)

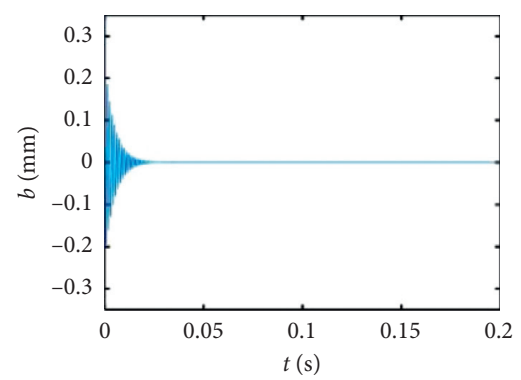

(f)

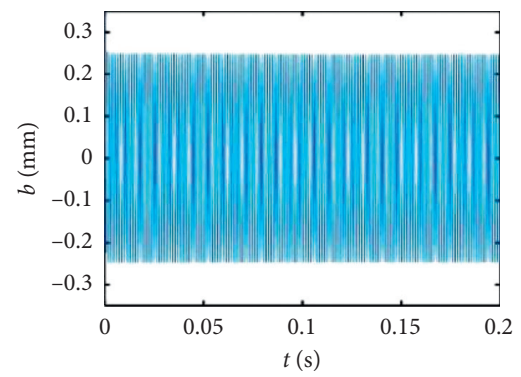

(i)

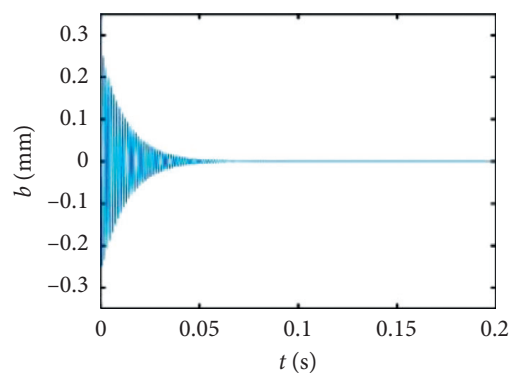

(l)

FIGURE 4: Time-history response curves at these parameter points.

corresponding to the stability boundary is reduced. This suggests that increasing length of the cutting bar imposes adverse effects on the cutting stability.

Figure 6 shows the effect of the diameter of the cutting bar on the boundary of the cutting stability. As observed, the stability of the cutting system drops as the diameter of the cutting bar increases. This can be attributed to the fact that the decrease in the diameter of the cutting bar leads to increased aspect ratio, indicating that the stability of the cutting bar is inversely proportional to the aspect ratio.

Figure 7 shows the effect of the dissipation factor of the cutting bar on the cutting stability boundary. As observed, improving the cutting bar's damping dissipation capacity is of great significance to suppressing cutting chatter and enhancing the stability in processing.

Figure 8 shows the effect of the cutting force coefficient on the cutting stability boundary. The nonlinear lobes are plotted, and the range of rotating speed is the same as that of linear lobes. As observed, the cutting stability decreased with the increase in $K_{t}$.

Figure 9 shows the effect of the ply angle $\theta$ on the lobe diagram of chatter stability. Apparently, with the increase in ply angle, the limit cutting depth of the composite boring bar drops gradually, accompanied by the reducing of stable 


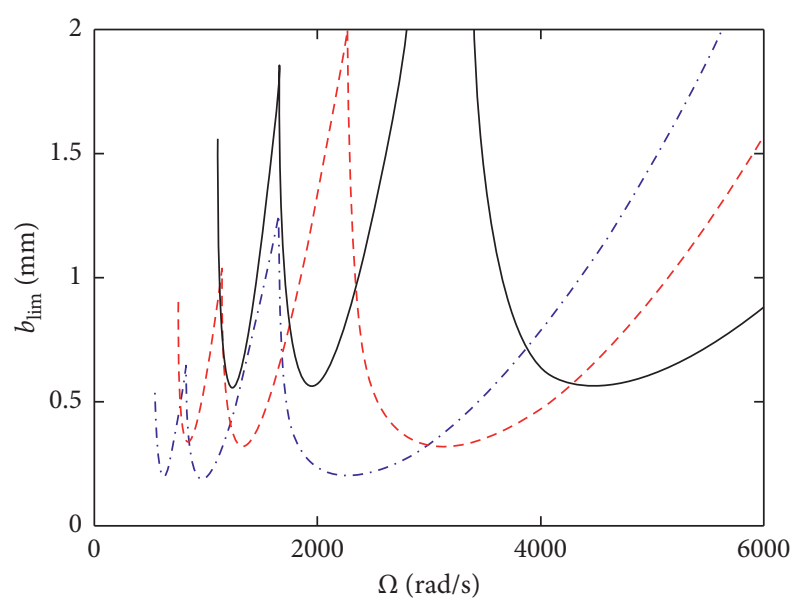

$$
\begin{aligned}
& \text { - } L=380 \mathrm{~mm} \\
& \text { - - } L=460 \mathrm{~mm} \\
& \text {... } L=540 \mathrm{~mm}
\end{aligned}
$$

Figure 5: Effect of the length of the cutting bar.

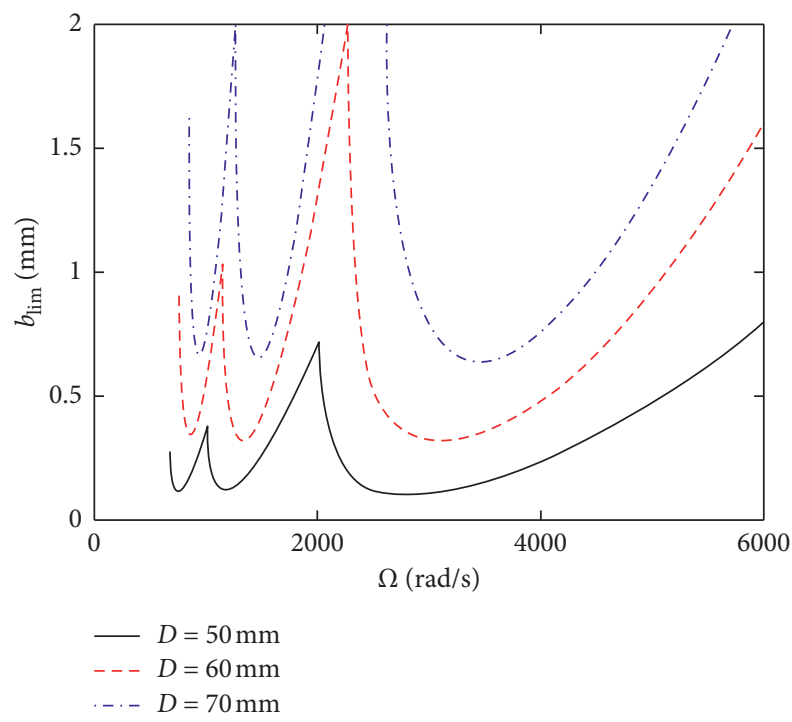

FIgURE 6: Effect of the diameter of the cutting bar.

regions. The stable regions reach a maximum at a ply angle of $0^{\circ}$, suggesting most favorable cutting stability.

3.2. Primary Resonance Response. In order to investigate nonlinear forced response characteristics of the cutting system, we calculate the forced response amplitude $\alpha$ at a given detuning parameter $\sigma$ using equation (30). The trend of $\alpha$ as a function of $\sigma$, namely, primary resonance response curve, is plotted, and the effects of parameters of the cutting system on primary resonance response are investigated.

Figure 10 shows the effect of $L$ on the primary resonance characteristics. The peak of the primary resonance curve deviated towards the right side, which has the behavior of typical Duffing's vibrator with hard spring. Jump and multivalue regions can be observed in primary resonance

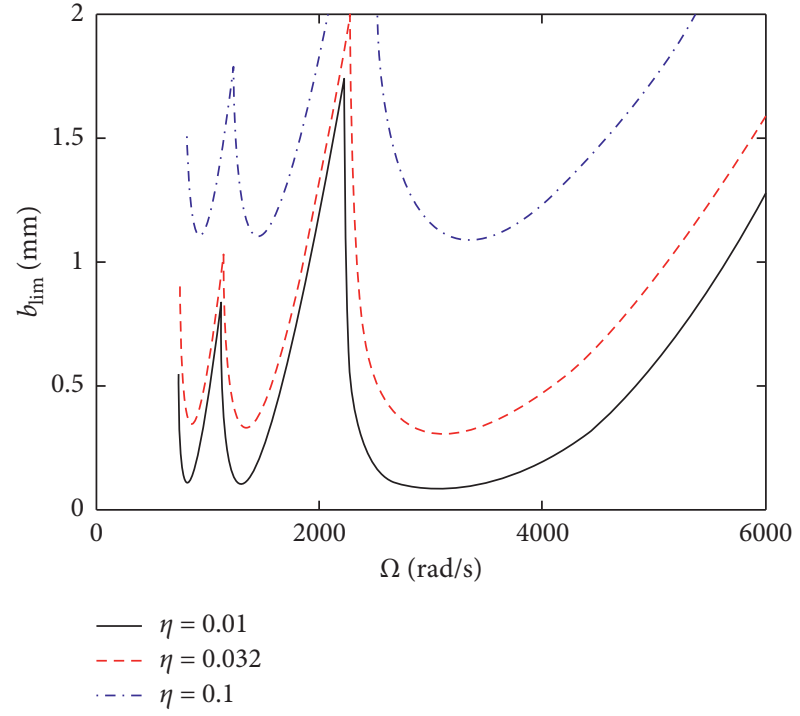

FIgURE 7: Effect of structural damping.

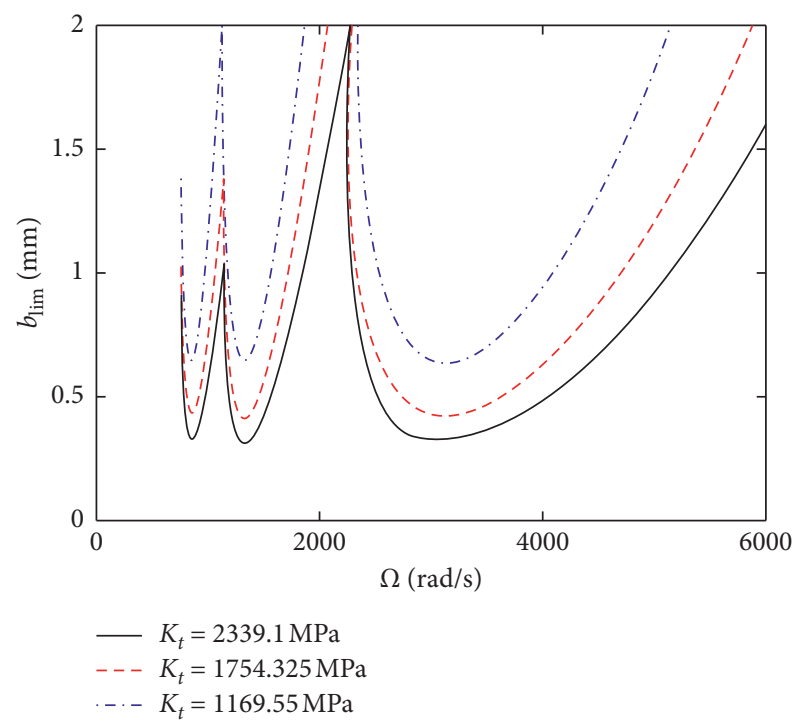

FIgURE 8: Effect of the cutting force coefficient.

curves. This can be attributed to cubic nonlinearity in the composite cutting bar. Meanwhile, nonlinear response characteristics are more significant for a short cutting bar which has small vibration amplitudes. Also, the structural nonlinearity limits the vibration amplitudes.

Figure 11 shows the effect of the diameter of the cutting bar on primary resonance response curves. The nonlinear behavior of the steady forced response became more pronounced by increasing diameter of the cutting bar. Indeed, the coefficient of the nonlinear term of the stiffness $\widehat{k} \beta_{2}$ is inversely proportional to the aspect ratio, according to equation (16). The aspect ratio is an important parameter that affects nonlinear response of the boring bar. Therefore, $\widehat{k} \beta_{2}$ is proportional to the diameter of the cutting bar, i.e., if values of the diameter of the cutting bar increase, the curves show stronger effects of nonlinearity. 


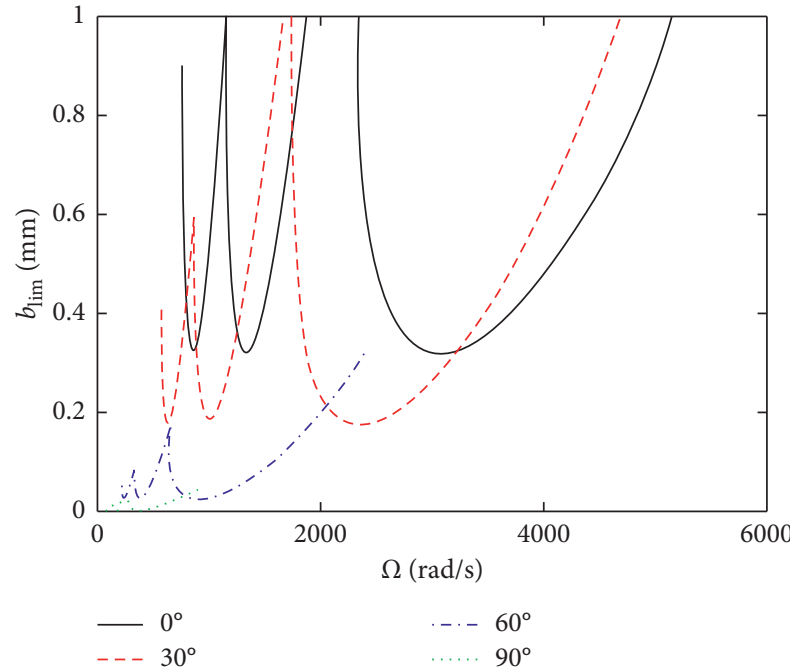

FIgURE 9: Effect of the ply angle on stability lobes.

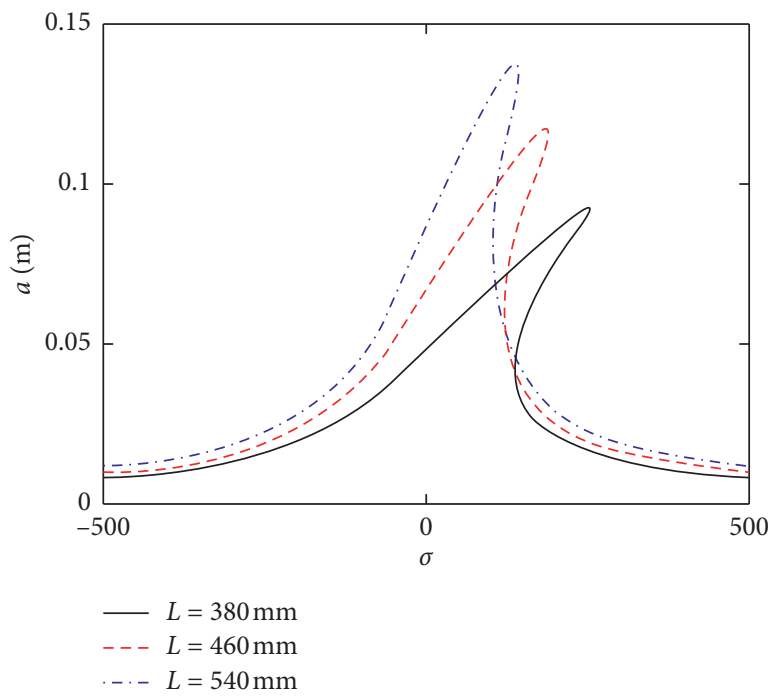

Figure 10: Effect of the length of the cutting bar on primary resonance curves.

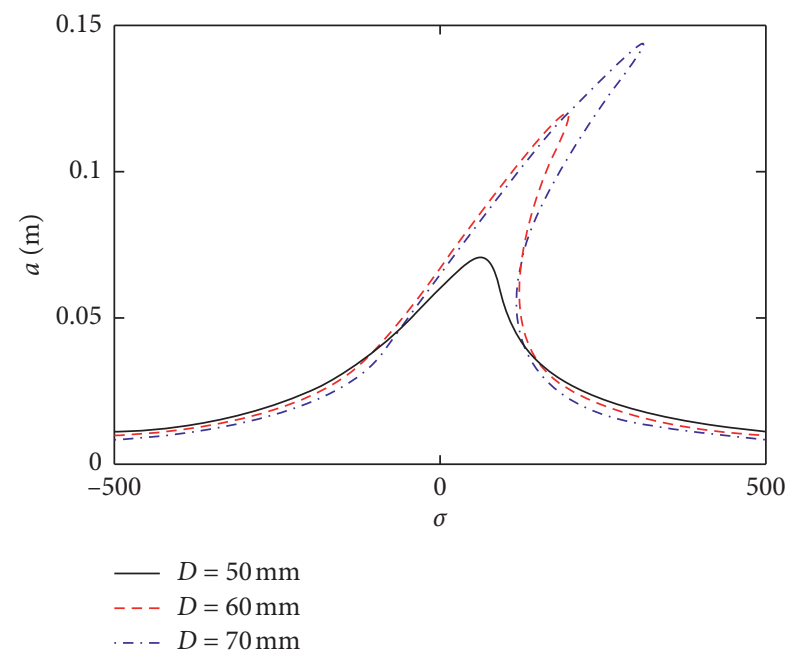

FIGURE 11: Effect of the diameter of the cutting bar on primary resonance curves.

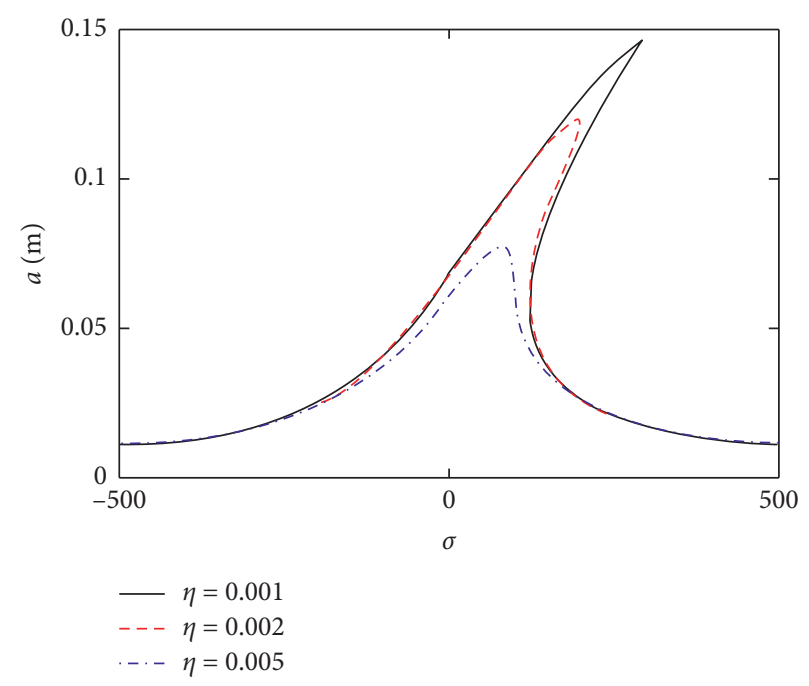

FIGURE 12: Effect of the structural damping bar on primary resonance curves.

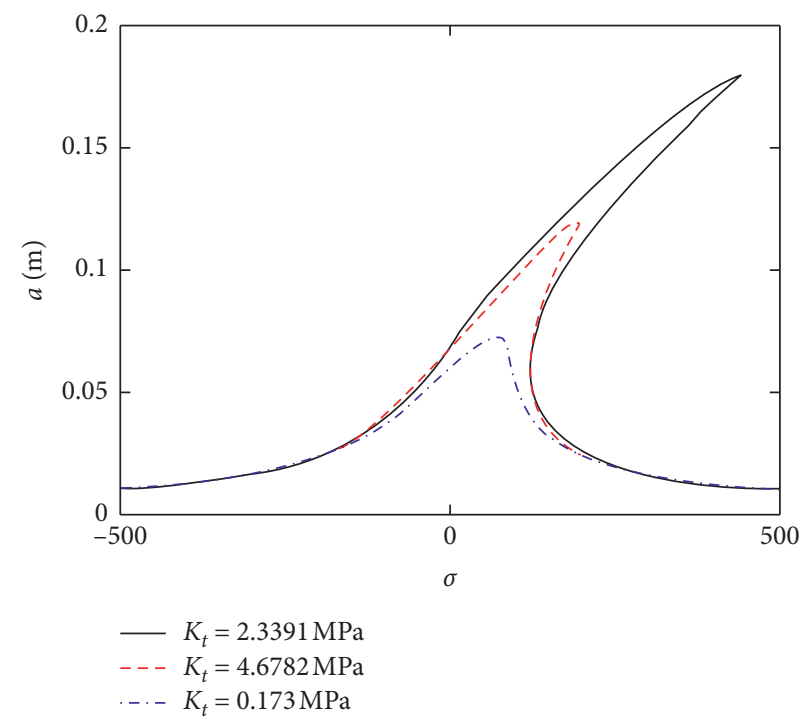

FIGURE 13: Effect of the cutting force parameter on primary resonance curves.

Figure 12 shows the dissipation factor $\eta$ on primary response curves. Apparently, the damping of the materials has a significant suppressing effect on the amplitude of primary resonance. This is due to the fact that the linear damping coefficient (as shown in equation (16)) is proportional to $\eta$ (see equations (14) and (15)). Therefore, increasing the dissipation factor leads to the increase in linear damping coefficient.

Figure 13 shows the effect of the cutting force parameter $K_{t}$ on the primary resonance curve. As it is observed, decreasing cutting force values leads to the decrease in vibration amplitudes.

The effect of the cutting depth $W_{c}$ on the primary resonance curve is shown in Figure 14. As it is shown, vibration amplitudes increase as the cutting depth decreases. Figure 15 shows the effect of amplitude of the periodic component in 


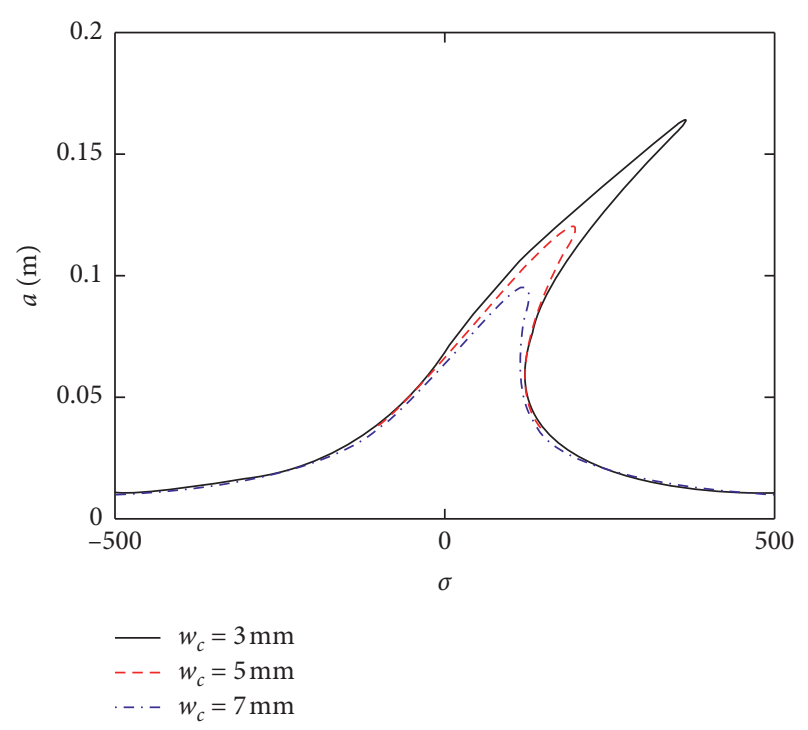

FIGURE 14: Effect of the cutting depth on primary resonance curves.

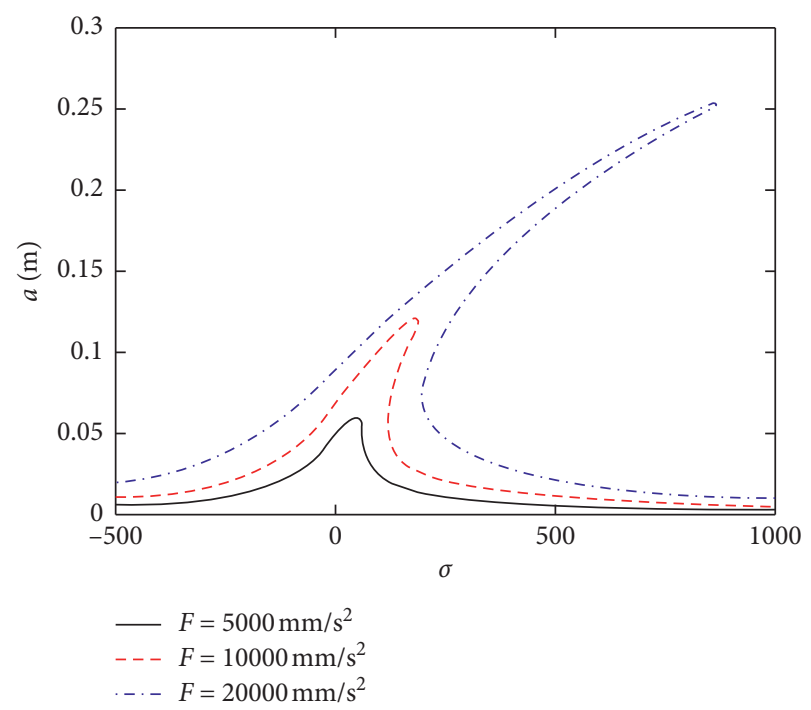

FIGURE 15: Effect of the amplitude of the periodic exciting force on primary resonance curves.

the cutting force $\widehat{F}$ on the primary resonance curve. As it is shown and physically expected, by increasing amplitude of cutting force, vibration amplitudes increase. Finally, the effect of the number of the cutting teeth $N$ on the primary resonance curve is shown in Figure 16. As it is observed, less vibration amplitudes can be achieved for the cutting system with less numbers of the cutting teeth.

Figure 17 shows the effect of the ply angle $\theta$ on primary resonance curves. As observed, the amplitude of primary resonance increases with the ply angle $\theta$. As shown in Table 1, the longitudinal elastic modulus of fiber $E_{11}$ significantly exceeded its transverse modulus $E_{22}$. Therefore, the bending stiffness of the axis EI and the nonlinear term

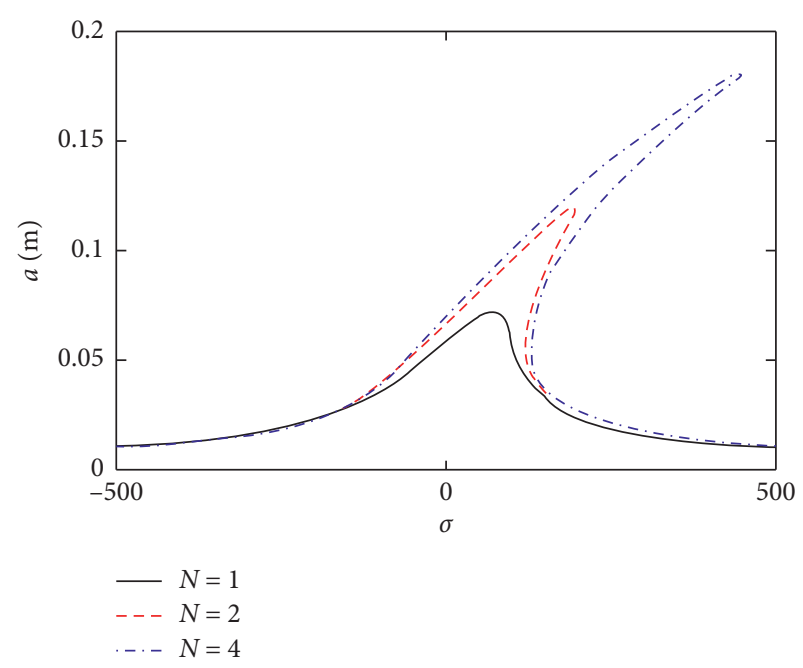

FIgURE 16: Effect of the number of the cutting teeth on primary resonance curves.

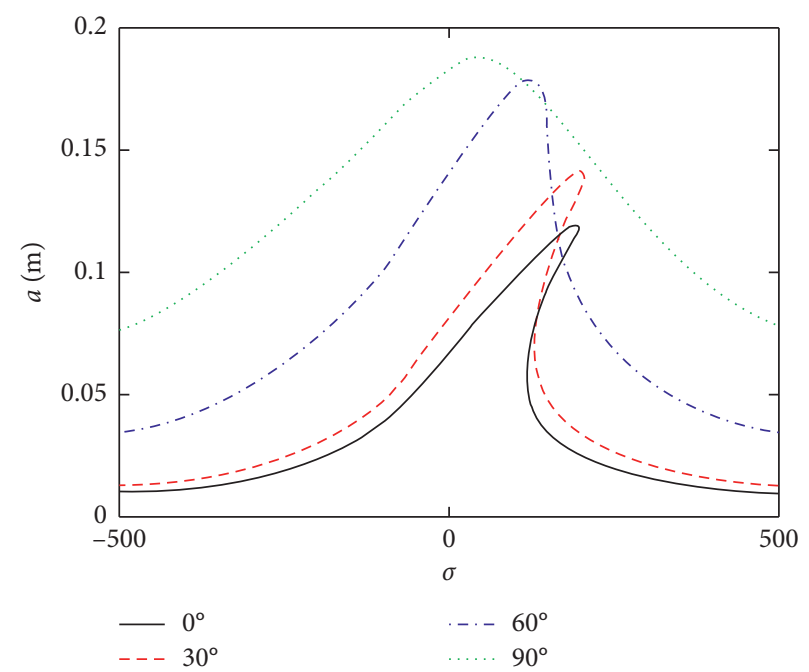

Figure 17: Effect of the ply angle on primary resonance curves.

coefficient $\widehat{k} \beta_{2}$ of the bar are inversely proportional to the ply angle.

Figure 18 shows the trends of the resonance amplitudes as a function of different parameters (including aspect ratio, dissipation factor cutting force coefficient, and ply angle) with different detuning parameters. In general, the system has a steady response solution for small values of the detuning parameter. For example, in the case of $\sigma=0$, for each value of aspect ratio, dissipation factor, cutting force coefficient, or ply angle, the cutting system has a single stable solution. However, multivalue response curves may be observed for larger values of the positive detuning parameter. For example, when $\sigma=150$ and $\theta<50^{\circ}$, the curves have 

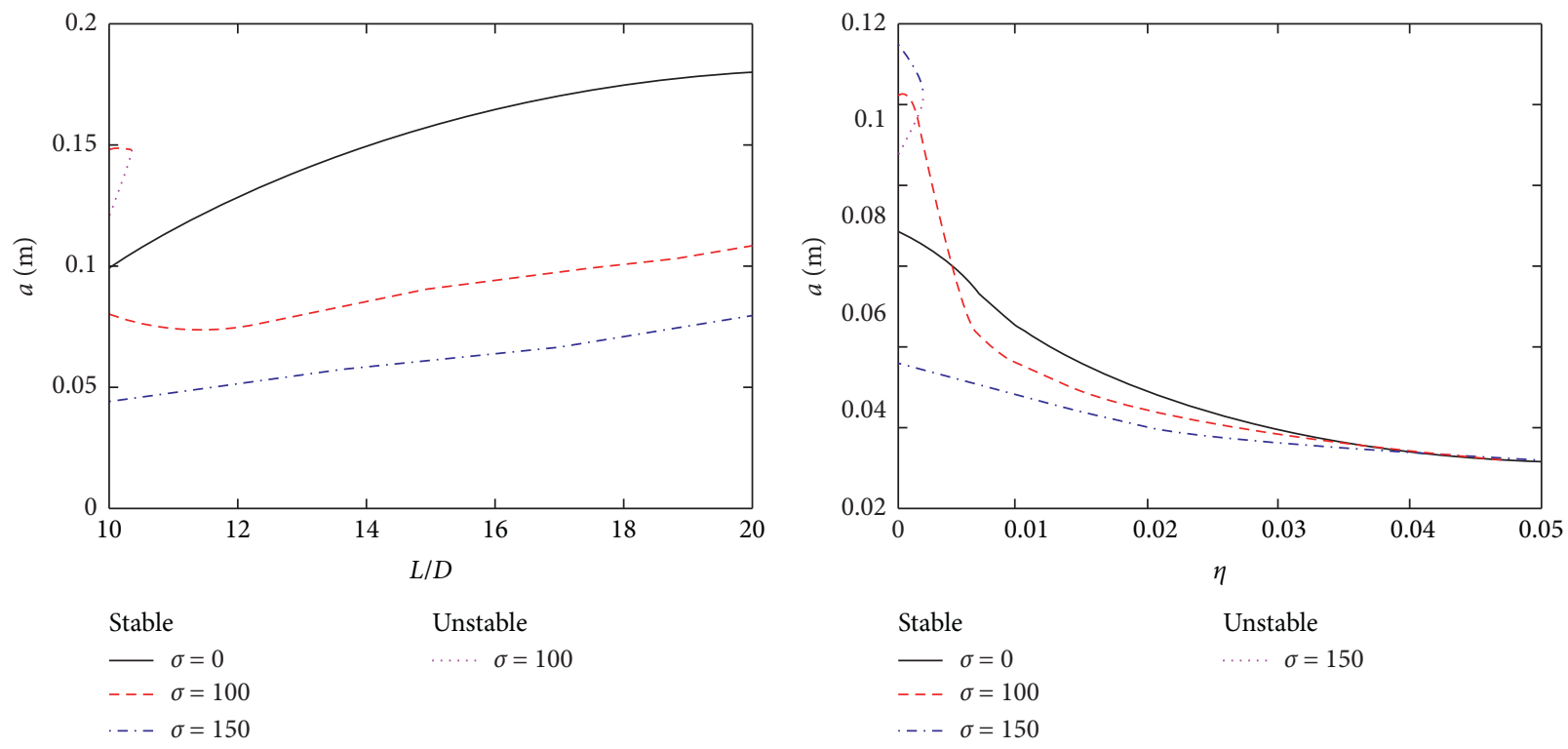

(a)

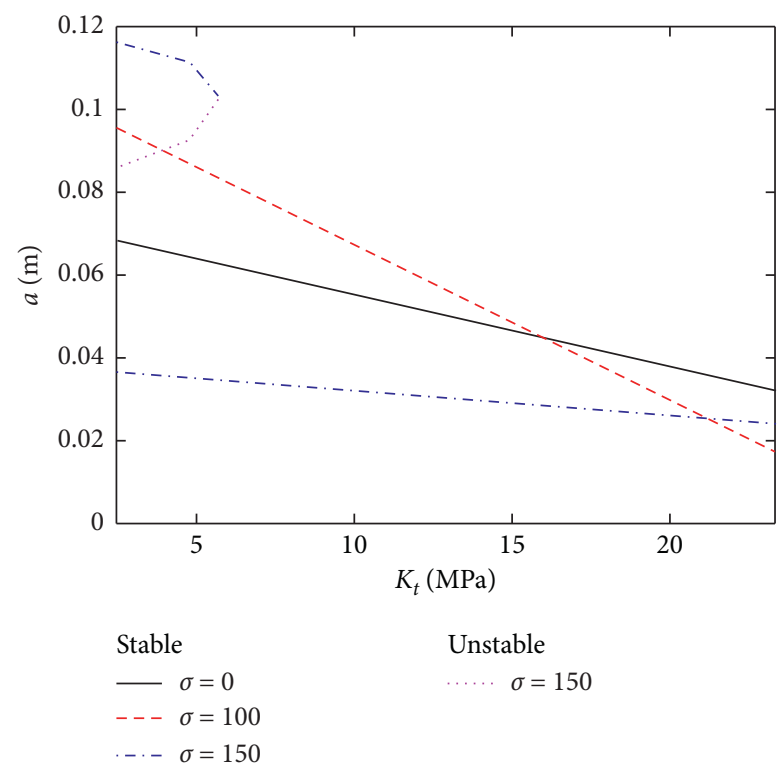

(c)

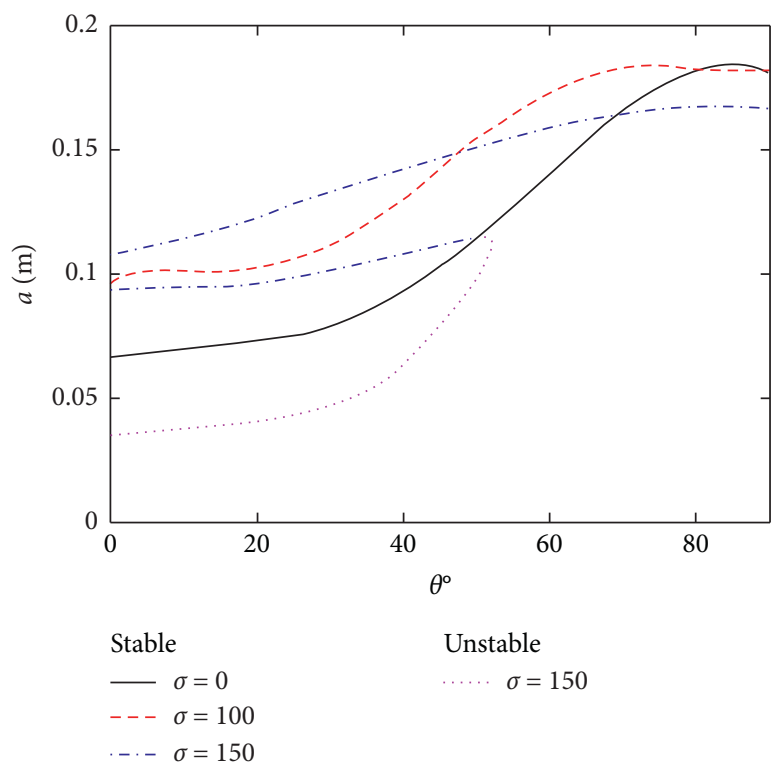

(d)

FIgURE 18: Trends of the amplitude as a function of the different factors at different values of the perturbation parameter: (a) Aspect ratio; (b) damping ratio; (c) cutting force coefficient; (d) ply angle.

two stable and one unstable branches. If $\sigma=150$ and $\theta>50^{\circ}$, there exists only one stable branch.

\section{Conclusions}

This study investigates nonlinear chatter and primary resonance of the milling system by taking into account the nonlinearity and damping of the cutting bar. The cutting bar is simplified as a plane-bending cantilever beam and made up of viscoelastic composite materials. Based on the Hamilton principle and the model of regenerative cutting force with periodic excitation, the one-dimensional nonlinear dynamic model of the cutting system is established. The motion equation is simplified using the Galerkin method, and the approximate solution to the primary resonance of the cutting system is obtained by the multiscale method. By numerical calculations, the lobes and primary resonance curves of the nonlinear cutting system are plotted. Moreover, the effects of various parameters, including the geometry of the cutting bar, structural damping, the cutting force coefficient, the cutting depth, the number of cutting teeth, the amplitude of cutting force, and the ply angle, on chatter stability and primary resonance characteristics are thoroughly investigated. The following conclusions can be drawn:

(1) The vibration amplitudes of the primary resonance curve is proportional to the number of cutting teeth 
and the amplitude of the exciting force and inversely proportional to the cutting force parameter and the cutting depth. The structural damping has a significant effect on the primary resonance response.

(2) Owing to the cubic nonlinearity of the composite cutting bar, the primary resonance peak shifts towards the right side. The primary resonance of the cutting system exhibits typical behavior of a hardspring Duffing's vibrator, while jump and multivalue regions are observed.

(3) Structural damping has a significant effect on the chatter stability of the cutting system. Good stability can be achieved for the cutting system with high coefficient of structural damping.

(4) The chatter stable region is expanded as the aspect ratio of the cutting bar (i.e., reducing the length or increasing the diameter) or when the system cutting force coefficient is reduced.

(5) When the process parameters are in unstable regions, time response of vibration cannot unlimitedly increase but converges to some finite values with time because of the existence of nonlinearity stiffness of the cutting bar. However, this has not been observed if a linear analysis model is used.

\section{Appendix}

$$
\begin{aligned}
\bar{Q}_{11}= & C_{11} \cos ^{4} \theta^{(k)}+C_{22} \sin ^{4} \theta^{(k)} \\
& +2\left(C_{12}+2 C_{66}\right) \sin ^{2} \theta^{(k)} \cos ^{2} \theta^{(k)},
\end{aligned}
$$

where

$$
\begin{aligned}
& C_{11}=\frac{E_{11}}{1-v_{12} v_{21}}, \\
& C_{11}=\frac{v_{12} E_{11}}{1-v_{12} v_{21}}=\frac{v_{21} E_{22}}{1-v_{12} v_{21}}, \\
& C_{22}=\frac{E_{22}}{1-v_{12} v_{21}}, \\
& C_{66}=G_{12}, \\
& v_{21}=\frac{v_{12} E_{11}}{E_{22}} .
\end{aligned}
$$

$\theta^{(k)}$ represents the layering angle of each layer.

\section{Data Availability}

The data used to support the findings of this study are available from the corresponding author upon request.

\section{Conflicts of Interest}

The authors declare that they have no potential conflicts of interest with respect to the research, authorship, and/or publication of this article.

\section{Acknowledgments}

This work was supported by the National Natural Science Foundation of China (NSFC) with grant no. 11672166.

\section{References}

[1] G. Tlusty, Manufacturing Process and Equipment, PrenticeHall, Englewood, CO, USA, 2000.

[2] K. Seto and N. Tominari, "Effect of a variable stiffness-type dynamic damper on machine tools with long overhung ram," Bulletin of JSME, vol. 19, no. 137, pp. 1270-1277, 1976.

[3] P. Den J and Hartog, Mechanical Vibrations, McGraw-Hill, New York, NY, USA, 1956.

[4] S. Ema and E. Marui, "Suppression of chatter vibration of boring tools using impact dampers," International Journal of Machine Tools and Manufacture, vol. 40, no. 8, pp. 1141-1156, 2008.

[5] S. Nagano, T. Koizumi, T. Fujii, N. Tsujiuchi, H. Ueda, and K. Steel, "Development of a composite boring bar," Composite Structures, vol. 38, no. 1-4, pp. 531-539, 1997.

[6] D. G. Lee and H. Yun Hwang, "Design and manufacture of a carbon fiber epoxy rotating boring bar," Composite Structures, vol. 60, no. 1, pp. 115-124, 2003.

[7] F. Taylor, "On the art of cutting metals," Transactions ASME, vol. 28, pp. 31-350, 1907.

[8] S. A. Tobias and W. Fishnick, "The chatter of lathe tools under orthogonal cutting conditions," Transactions of the American Society of Mechanical Engineers, vol. 80, pp. 1079-1086, 1958.

[9] H. E. Merritt, "Theory of self-excited machine tool chatter, condition to machine tool chatter research-1, Transactions of the American Society of Mechanical Engineers," Journal of Engineering for Industry, vol. 87, pp. 447-545, 1963.

[10] S. Kato and E. Marui, "On the cause of regenerative chatter due to workpiece deflection," Journal of Engineering for Industry, vol. 96, no. 1, pp. 179-186, 1974.

[11] D. W. Wu and C. R. Liu, "An analytical model of cutting dynamics. Part 1: model building," Journal of Engineering for Industry, vol. 107, no. 2, pp. 107-111, 1985.

[12] Y. Altintas, Manufacturing Automation, Metal Cutting Mechanics, Machine Tool Vibrations, and CNC Design, Cambridge University Press, New York, NY, USA, 2000.

[13] E. Budak and Y. Altintas, "Analytical prediction of chatter stability in milling-part I: general formulation," Journal of Dynamic Systems, Measurement, and Control, vol. 120, no. 1, pp. 22-30, 1998.

[14] E. Budak and Y. Altintas, "Analytical prediction of chatter stability in milling-part II: application of the general formulation to common milling systems," Journal of Dynamic Systems, Measurement, and Control, vol. 120, no. 1, pp. 31-36, 1998.

[15] N. H. Hanna and S. A. Tobias, "A theory of nonlinear regenerative chatter," Journal of Engineering for Industry, vol. 96, no. 1, pp. 247-255, 1974.

[16] L. Vela-Martínez, J. C. Jáuregui-Correa, O. M. González-Brambila, G. Herrera-Ruiz, and A. LozanoGuzmán, "Instability conditions due to structural nonlinearities in regenerative chatter," Nonlinear Dynamics, vol. 56, no. 4, pp. 415-427, 2009.

[17] N. Deshpande and M. S. Fofana, "Nonlinear regenerative chatter in turning," Robotics and Computer-Integrated Manufacturing, vol. 17, no. 1-2, pp. 107-112, 2001.

[18] G. Stépán and T. Insperger, "Delay, parametric excitation, and the nonlinear dynamics of cutting processes," International 
Journal of Bifurcation and Chaos, vol. 15, no. 9, pp. 2783-2798, 2005.

[19] H. Moradi and M. R. Movahhedy, "Bifurcation analysis of milling process with tool wear and process damping: regenerative chatter with primary resonance," Nonlinear Dynamics, vol. 70, no. 1, pp. 481-509, 2012.

[20] H. Moradi and M. R. Movahhedy, "Dynamics of regenerative chatter and internal resonance in milling process with structural and cutting force nonlinearities," Journal of Sound and Vibration, vol. 331, no. 16, pp. 3844-3865, 2012.

[21] H. Moradi, G. Vossoughi, M. R. Movahhedy, and M. T. Ahmadian, "Forced vibration analysis of the milling process with structural nonlinearity, internal resonance, tool wear and process damping effects," International Journal of Non-linear Mechanics, vol. 54, pp. 22-34, 2013.

[22] M. M. Jalili and J. Hesabi, "Simulation of forced vibration in milling process considering gyroscopic moment and rotary inertia," The International Journal of Advanced Manufacturing Technology, vol. 89, no. 9-12, pp. 2821-2836, 2017.

[23] J. Abootorabi and C. Ngo, "Nonlinear modeling and dynamic simulation using bifurcation and stability analyses of regenerative chatter of ball-end milling process," Mathematical Problems in Engineering, vol. 2016, Article ID 4368680, 2016.

[24] W. Zhang, F.-X. Wang, and J. W. Zu, "Local bifurcations and codimension-3 degenerate bifurcations of a quintic nonlinear beam under parametric excitation," Chaos, Solitons and Fractals, vol. 24, no. 4, pp. 977-998, 2005.

[25] M. Yao and W. Zhang, "Multipulse Shilnikov orbits and chaotic dynamics for nonlinear nonplanar motion of a cantilever beam," International Journal of Bifurcation and Chaos, vol. 15, no. 12, pp. 3923-3952, 2011.

[26] M. Yao, W. Zhang, and J. W. Zu, "Multi-pulse chaotic dynamics in non-planar motion of parametrically excited viscoelastic moving belt," Journal of Sound and Vibration, vol. 331, no. 11, pp. 2624-2653, 2012.

[27] W. Zhang, R. Zhou, and W. Zu Jean, "Nonlinear vibrations of a shell-shaped workpiece during high-speed milling process," Nonlinear Dynamics, vol. 4, no. 72, pp. 767-787, 2013.

[28] R. Zhou, W. Zhang, and W. Zu Jean, "Analysis on nonlinear dynamics of a thin-plate workpiece in milling process with cutting force nonlinearities," Journal of Mechanical Science and Technology, vol. 7, no. 28, pp. 2511-2526, 2014.

[29] T. J. Yu, W. Zhang, and X. D. Yang, "Global dynamics of an autoparametric beam structure," Nonlinear Dynamics, vol. 2, no. 88, pp. 1329-1343, 2017.

[30] J. R. Pratt, Vibration control for chatter suppression, $\mathrm{PhD}$ Thesis, Virginia Polytechnic Institute and State University, Blacksburg, VA, USA, 1997.

[31] W. Zhang, F. Wang, and M. Yao, "Global bifurcations and chaotic dynamics in nonlinear nonplanar oscillations of a parametrically excited cantilever beam," Nonlinear Dynamics, vol. 40, no. 3, pp. 251-279, 2005.

[32] W. Zhang, "Chaotic motion and its control for nonlinear nonplanar oscillations of a parametrically excited cantilever beam," Chaos, Solitons and Fractals, vol. 26, no. 3, pp. 731-745, 2005.

[33] D. A. Saravanos, D. Varelis, T. S. Plagianakos, and N. Chrysochoidis, "A shear beam finite element for the damping analysis of tubular laminated composite beams," Journal of Sound and Vibration, vol. 291, no. 3-5, pp. 802-823, 2006. 